\title{
A CPW-Fed Monopole Antenna with Double Rectangular Rings and Vertical Slots in the Ground Plane for WLAN/WiMAX Applications
}

\author{
Sangiin Jo, Hyunjin Choi, Jaehyuk Lim, Beomsoo Shin, Sangyeol Oh, and Jaehoon Lee \\ Department of Computer and Radio Communication Engineering, Korea University, 15 Ka Anam-Dong, Seongbuk-gu, \\ Seoul 136-701, Republic of Korea \\ Correspondence should be addressed to Jaehoon Lee; ejhoon@korea.ac.kr \\ Received 15 April 2015; Revised 15 June 2015; Accepted 15 June 2015 \\ Academic Editor: Junping Geng \\ Copyright (C) 2015 Sangjin Jo et al. This is an open access article distributed under the Creative Commons Attribution License, \\ which permits unrestricted use, distribution, and reproduction in any medium, provided the original work is properly cited.
}

A compact triple-band monopole antenna consisting of double rectangular rings and vertical slots cut into the ground is proposed for WLAN and WiMAX operations. The antenna has a compact size of $27.1 \times 38.8 \times 1.6 \mathrm{~mm}^{3}$, with simulated and measured impedance bandwidths of 2.37 2.81, 3.21 3.82, and 4.61 6.34 GHz with a reflection coefficient of less than $-10 \mathrm{~dB}$. The antenna also exhibits an almost omnidirectional radiation pattern and stable gain levels in the triple bands. The characteristics of the proposed antenna have been investigated using the numerical simulations and experiments.

\section{Introduction}

Recently, there has been rapid progress in wireless communications technology employing various frequency bands. For short-range and long-range communication applications, many antenna designs have been studied that are suitable for wireless local area network (WLAN) and worldwide interoperability for microwave access (WiMAX) operation. There is also a growing demand in wireless communication technology for integration of the WLAN $(2.412 \sim 2.482 \mathrm{GHz}$, $5.15 \sim 5.825 \mathrm{GHz})$ and WiMAX $(2.500 \sim 2.690 \mathrm{GHz}, 3.400 \sim$ $3.690 \mathrm{GHz}, 5.250 \sim 5.850 \mathrm{GHz}$ ) frequency bands into a single device, thus necessitating the development of multiband antennas with simple structure and low profile. Numerous multiband antenna designs with simple structure have already been reported, including a printed planar wide-slot antenna [1], a CPW-fed planar monopole antenna [2], a printed inverted-L- (IL-) shaped monopole antenna [3], a slot-monopole antenna with embedded rectangular parasitic elements [4], and a monopole antenna with a split ring [5]. However, for the realization of multiband operation, additional structures must be employed on the bottom layer such as a T-shape, S-shape, vertical strip resonator, or parasitic elements.

In this paper, we propose a $\mathrm{CPW}$ double rectangular ring-shaped monopole antenna design that incorporates the frequency bands for WLAN and WiMAX applications (i.e., operates at frequencies in the ranges 2.4 2.690, 3.4 3.69, and $5.15 \sim 5.850 \mathrm{GHz})$. Triple band characteristics are achieved by an inner/outer ring structures and thin slots in the ground plane. The outer ring structure controls the resonance at the lower and upper frequency bands, whereas the inner ring structure controls the resonance at the middle frequency band. Two thin slots etched into the ground are used to reject an unwanted resonance at around $4 \mathrm{GHz}$. Details of the proposed antenna design and experimental results are presented and discussed.

\section{Antenna Design}

The geometry of the CPW-fed double rectangular ringshaped antenna is shown in Figure 1, together with a photograph of the fabricated optimized structure. The antenna has overall dimensions of $27.1 \times 38.8 \times 1.6 \mathrm{~mm}^{3}$ and was 


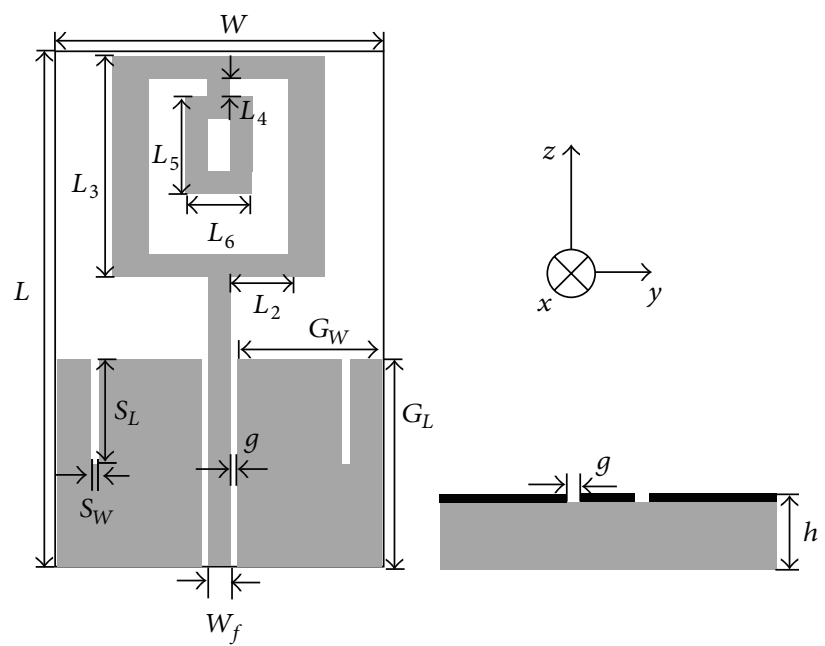

(a)

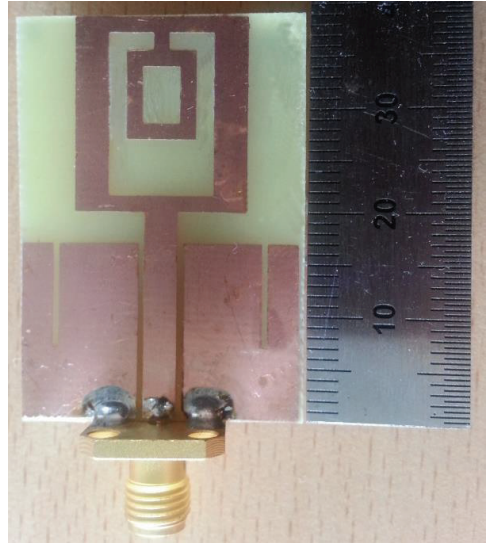

(b)

FIGURE 1: Geometry and photograph of the proposed antenna: (a) geometry, (b) photograph.

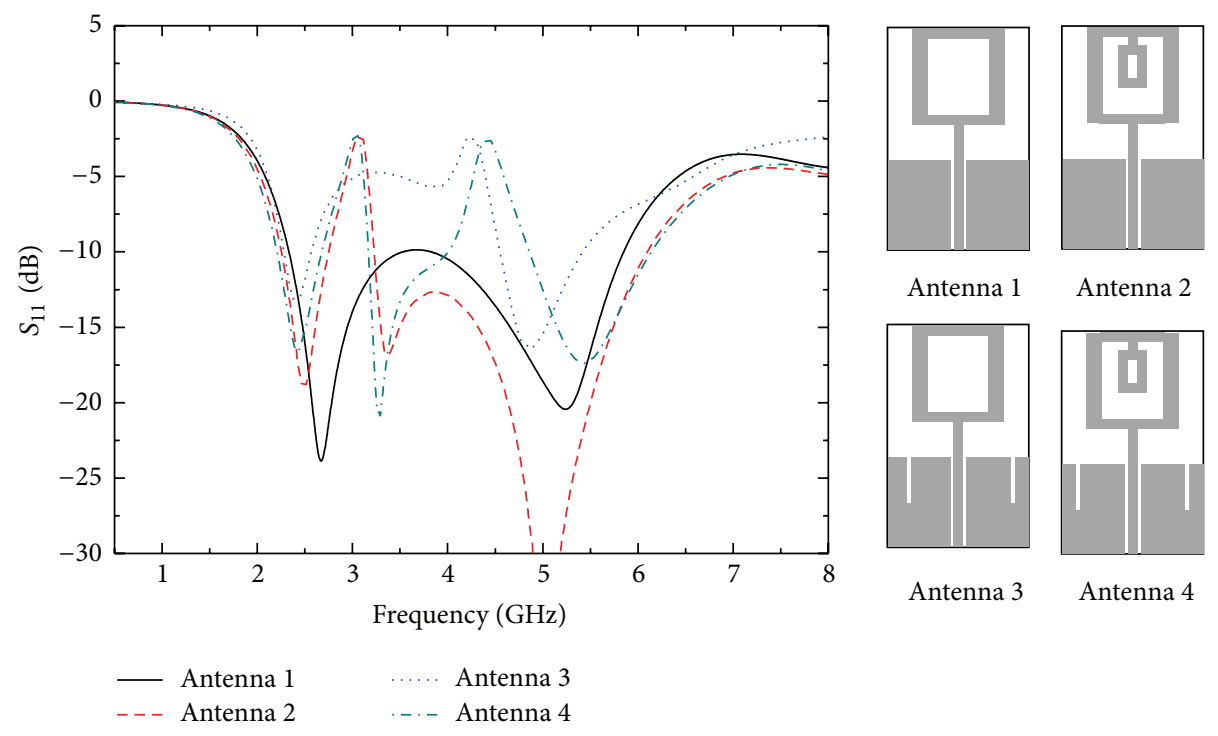

FIgURE 2: Simulated return losses for the proposed antenna with and without the inner ring and vertical slots.

fabricated on an FR4 substrate with relative permittivity $\varepsilon_{r}=4.4$. A $50 \Omega \mathrm{CPW}$ transmission line with a signal strip width of $3.5 \mathrm{~mm}$ and a gap distance of $0.3 \mathrm{~mm}$ is used to feed the antenna. Two ground planes of the CPW line with dimensions of $11.5 \times 17 \mathrm{~mm}^{2}$ are situated symmetrically on either side of the CPW line. The size of the outer rectangular ring is $17 \times 21.8 \mathrm{~mm}^{2}$, and the size of the inner ring is 7 $\times 8.8 \mathrm{~mm}^{2}$. The antenna consists of a single-layer metallic structure for the simple fabrication, which is etched onto one side of the substrate. The optimal design parameters in Figure $1(\mathrm{a})$ are $W=27.1 \mathrm{~mm}, L=38.8 \mathrm{~mm}, G_{W}=11.5 \mathrm{~mm}$, $G_{L}=17.0 \mathrm{~mm}, W_{f}=3.5 \mathrm{~mm}, g=0.3 \mathrm{~mm}, h=1.6 \mathrm{~mm}$,
$L_{1}=2.8 \mathrm{~mm}, L_{2}=8.5 \mathrm{~mm}, L_{3}=19.0 \mathrm{~mm}, L_{4}=5.0 \mathrm{~mm}$, $L_{5}=7.0 \mathrm{~mm}, L_{6}=7.0 \mathrm{~mm}, S_{L}=10.0 \mathrm{~mm}$, and $S_{W}=$ $0.3 \mathrm{~mm}$.

Figure 2 shows the effects on the return losses produced by the inner ring and the vertical slots in the ground plane via numerical simulations. Antenna 1 (in Figure 2), which consists solely of the outer rectangular ring, can easily achieve resonances at two frequency bands for dualband WLAN operation [6]. In Antenna 2, which the inner rectangular ring is added, we found that it can excite a middle frequency of $3 \mathrm{GHz}$. However, the addition of the inner rectangular ring also produces wideband resonances 


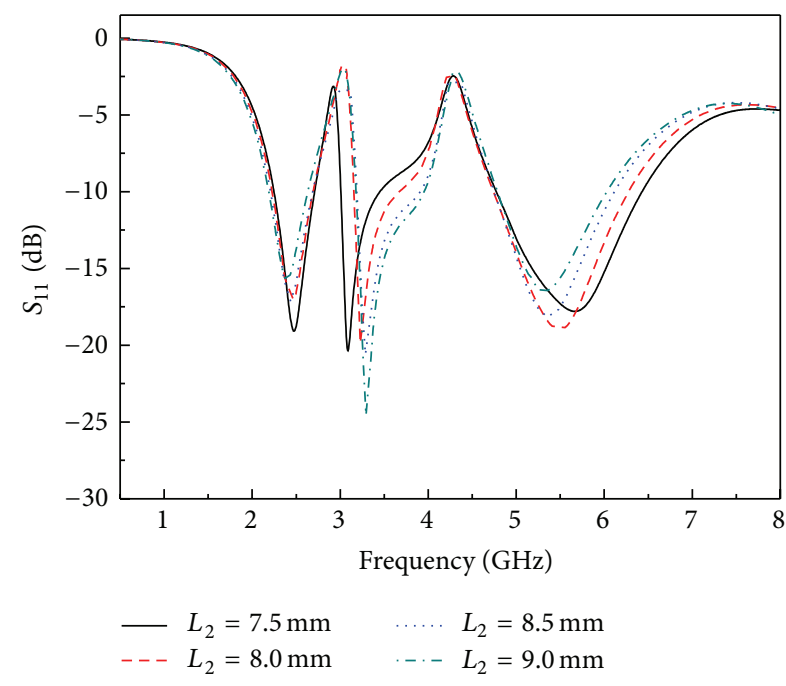

(a)

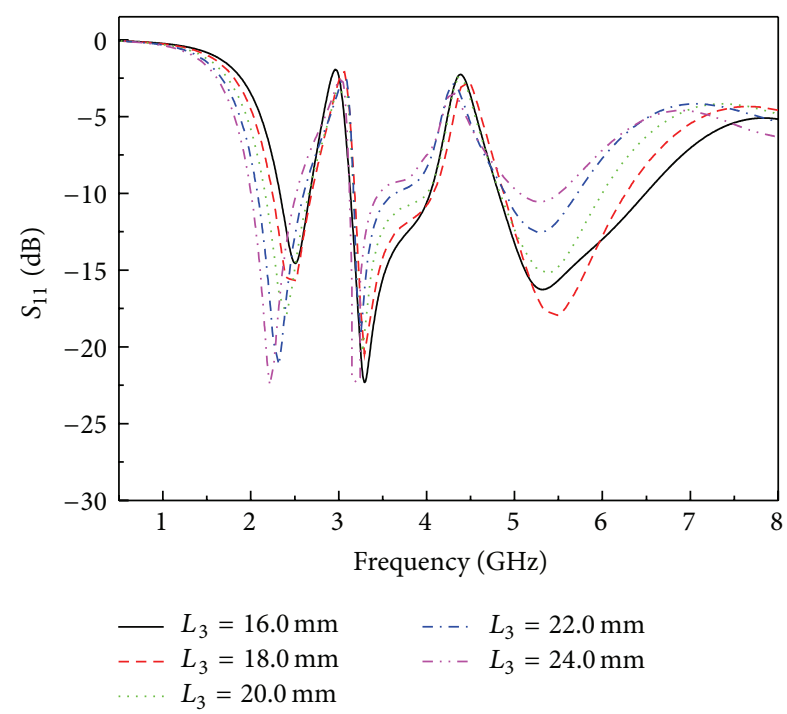

(b)

FigURE 3: Influence of the outer ring on the return loss of the proposed antenna: (a) various $L_{2}$ when $L_{3}=19 \mathrm{~mm}$, (b) various $L_{3}$ when $L_{2}=8.5 \mathrm{~mm}$.

in frequency bands around $4 \mathrm{GHz}$ where they are not wanted. In Antenna 3, which vertical slots are inserted into the ground plane of Antenna 1, band-notched frequencies appear around $4 \mathrm{GHz}$, and the resonance in the notched band from 4.0 to $5.0 \mathrm{GHz}$ is removed. The lengths of these slots are equal to the half-guided wavelength at the rejected frequency $[7,8]$. Finally, the proposed doublerectangular-ring antenna with double rectangular rings and vertical slots in the ground plane (Antenna 4) can generate three distinct resonances in three wanted separate frequency bands.

In the aforementioned, the lower and upper frequency bands are primarily determined by the outer ring and the middle frequency band is dominated by the inner ring. Figure 3 shows the influence of the geometries of the outer ring on the return loss at the lower and upper frequency bands in the proposed antenna. Figure 3(a) shows the effect of $L_{2}$ when the length, $L_{3}$, of the outer ring was fixed at $19 \mathrm{~mm}$ and Figure 3(b) shows the effect of $L_{3}$ when $L_{2}=8.5 \mathrm{~mm}$. Since, the parameter $L_{2}$ made a primary impact on not the lower and but the upper frequency band and the parameter $L_{3}$ made the frequency shift in the upper and lower bands at the same time, we adjusted the length of $L_{2}$ to finely tune the upper frequency band.

For the adjustment of the middle frequency bands, we adjusted the geometries of the inner ring as shown in Figure 4 . Figure 4 shows the effects of varying lengths of the rectangular inner ring, and $L_{4}, L_{5}$, and $L_{6}$ cannot make any variation at the lower and upper frequency bands when the parameters of the outer ring are fixed. As the parameters $L_{4}$, $L_{5}$, and $L_{6}$ increased, the middle resonant frequencies were decreased.

\section{Experiment Result}

Figure 5 shows the simulated and measured return losses of the proposed antenna with the optimized parameters, and good agreement between simulation and measurement is observed. For a $10 \mathrm{~dB}$ return loss, the measured impedance bandwidths of the three individual operating bands are about $500 \mathrm{MHz}(2.37 \sim 2.81 \mathrm{GHz}), 800 \mathrm{MHz}(3.21 \sim 3.82 \mathrm{GHz})$, and $1 \mathrm{GHz}(4.61 \sim 6.34 \mathrm{GHz})$, simultaneously covering the 2.4/5.2/5.8 GHz WLAN and 2.5/3.5/5.5 GHz WiMAX operational bands.

Figure 6 shows the simulated current distributions under the optimized structure at the different frequencies. The current distributions varied significantly depending on the resonant frequency. It is evident from these current distributions that, at lower frequency band, the radiation mainly resulted from the outer ring, as shown in Figure 6(a). The inner ring mainly contributes the radiation at middle frequency band, as shown in Figure 6(b). Likewise, the horizontal strip line of the outer ring mainly contributes the radiation at upper frequencies band, as shown in Figure 6(c).

The measured $X Y$-plane and $Z X$-plane radiation patterns are shown in Figure 7. The $X Y$-plane patterns appear to be nearly omnidirectional, whereas the $Z X$-plane patterns are in the broadside direction at all operating frequencies. Figure 8 shows the measured peak gain of the proposed antenna in the $2.4 \mathrm{GHz}, 3.5 \mathrm{GHz}$, and $5.5 \mathrm{GHz}$ bands. The measured peak realized gain levels of the antenna are about 5.5, 4.0 and $3.5 \mathrm{dBi}$ for $2.4,3.5$ and $5.5 \mathrm{GHz}$, respectively.

\section{Conclusion}

We proposed a CPW-fed monopole antenna with double rectangular rings and vertical slots for WLAN/WiMAX 

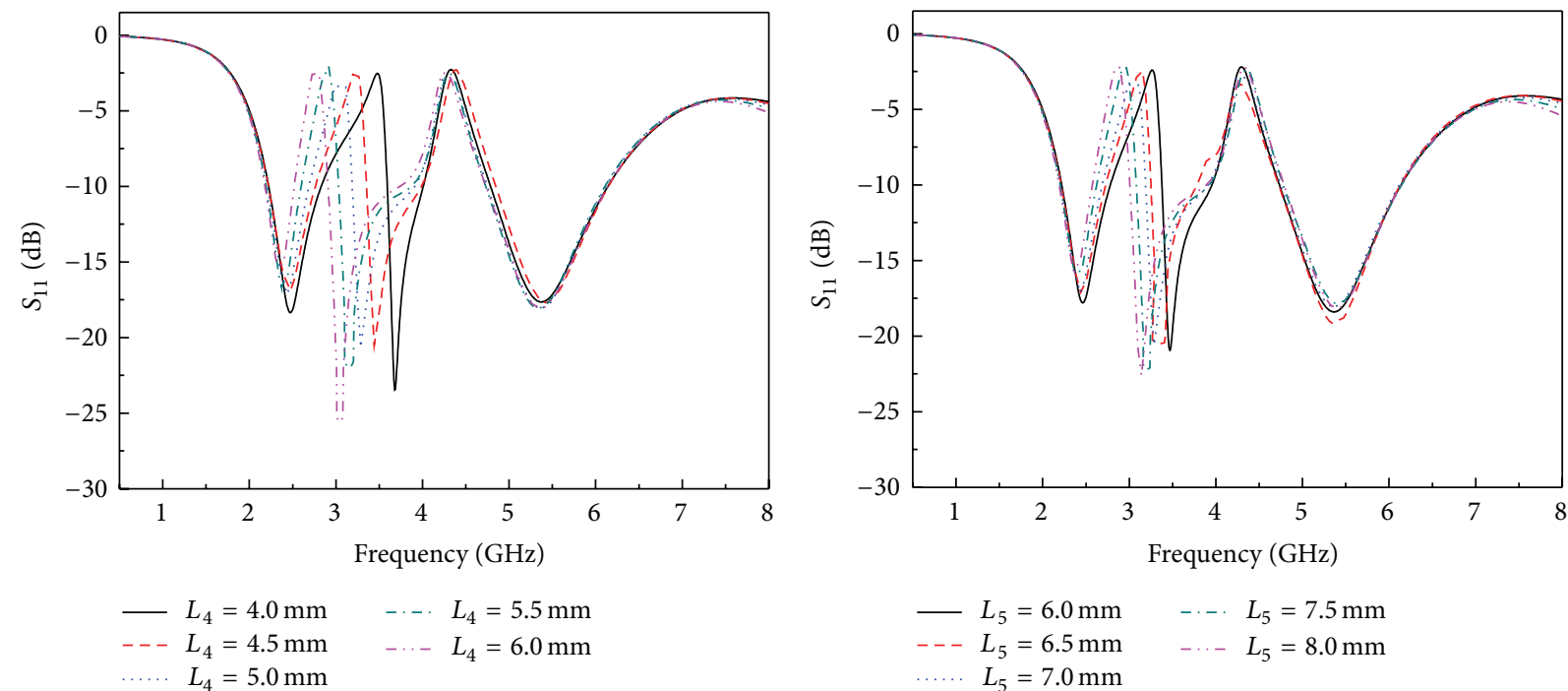

(a)

(b)

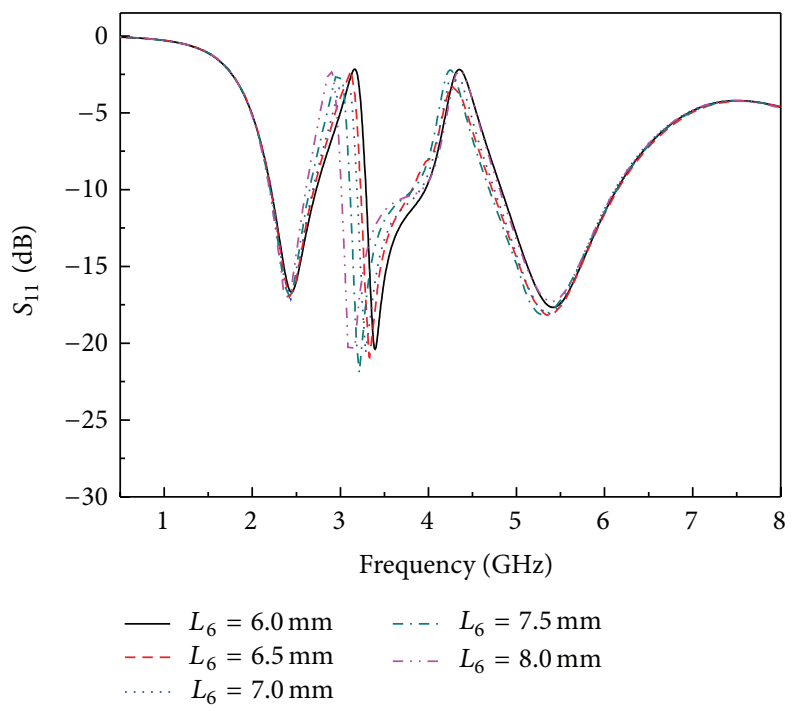

(c)

FIGURE 4: Influence of the inner ring on the return loss of proposed antenna: (a) various $L_{4}$ when $L_{5}=7 \mathrm{~mm}$ and $L_{6}=7 \mathrm{~mm}$, (b) various $L_{5}$ when $L_{4}=5 \mathrm{~mm}$ and $L_{6}=7 \mathrm{~mm},(\mathrm{c})$ and various $L_{6}$ when $L_{4}=5 \mathrm{~mm}$ and $L_{5}=7 \mathrm{~mm}$.

applications. The antenna design is compact, with dimensions of only $27.1 \times 38.8 \times 1.6 \mathrm{~mm}^{3}$. A band notch for unwanted frequency bands is achieved by adding vertical slots to the ground plane. The antenna has a simple geometry and is relatively easy to fabricate because of its single-layer metallic structure. Because the bandwidths of the lower, middle, and upper bands of the proposed monopole antenna are sufficient to cover the $2.4,3.5$, and $5.5 \mathrm{GHz}$ bands, the design is suitable for WLAN/WiMAX triple-band applications. Additionally, the proposed antenna provides good radiation patterns and stable gain in each of the operating bands.

\section{Conflict of Interests}

The authors declare that there is no conflict of interests regarding the publication of this paper.

\section{Acknowledgment}

This work was supported by the Basic Science Research Program through the National Research Foundation of Korea (NRF), funded by the Ministry of Education, Science, and Technology, Republic of Korea (NRF-2012R1A1B3002517 and NRF-2015R1A2A2A01005676). 


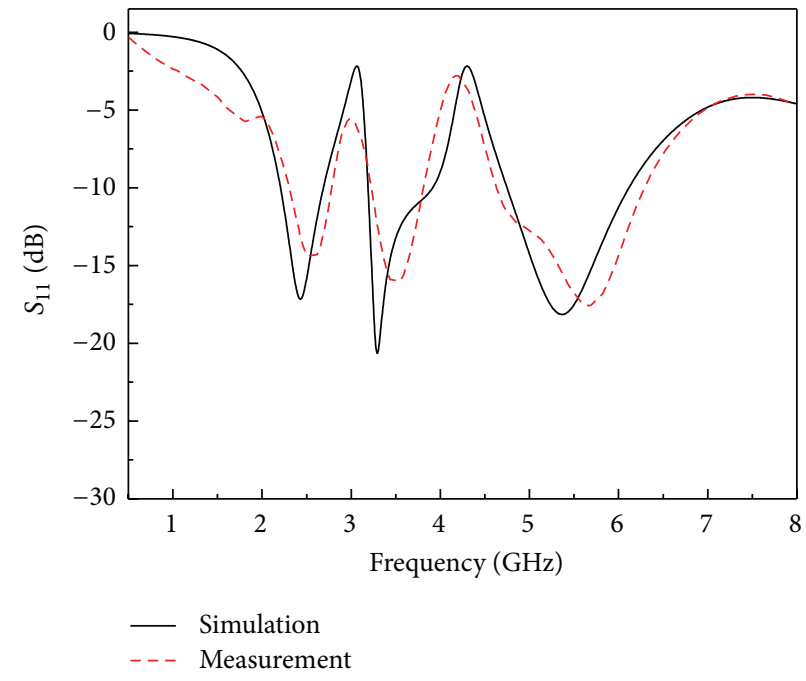

FIGURE 5: Measured and simulated reflection coefficients of the proposed antenna.

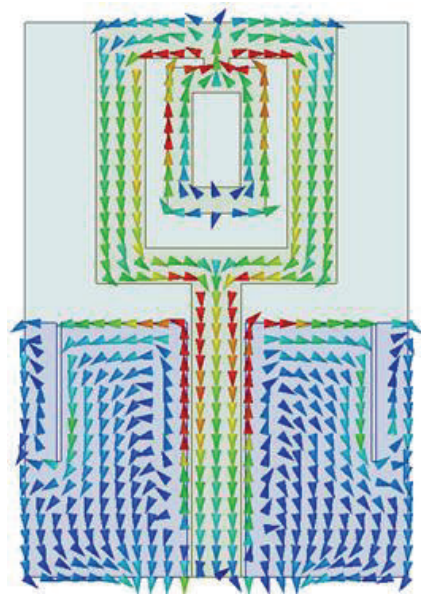

(a)

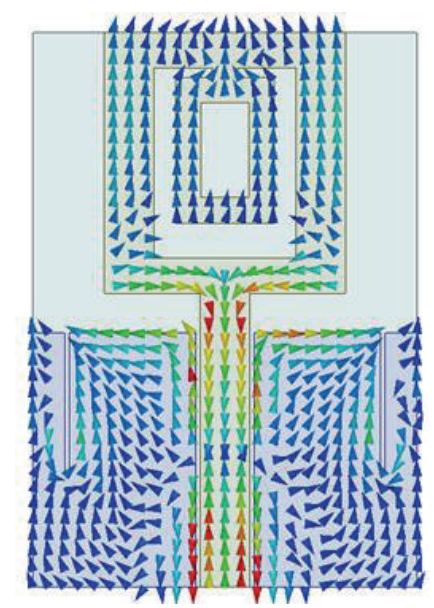

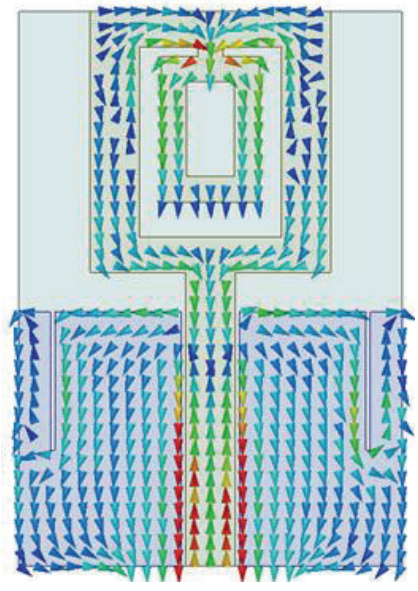

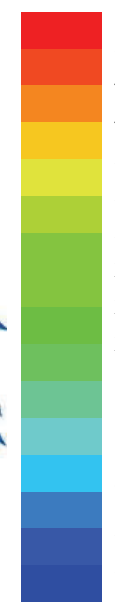

$5.0000 e+001$ $4.6432 e+001$ $4.2864 e+001$ $3.9296 e+001$ $3.5729 e+001$ $3.2161 e+001$ $2.8593 e+001$ ह $2.5025 e+001 \gtreqless$ $2.1457 e+001$ $1.7889 e+001$ $1.4321 e+001$ $1.0754 e+001$ $7.1857 e+000$ $3.6179 e+000$ $5.0000 e-002$

(c)

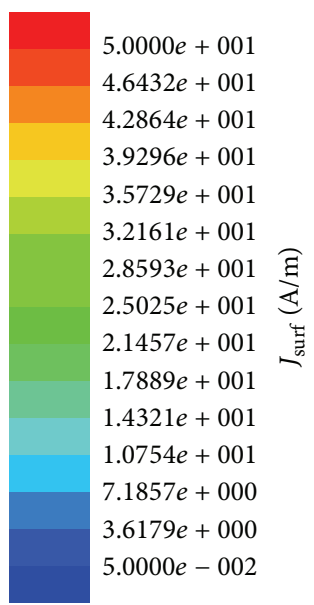

(b) 

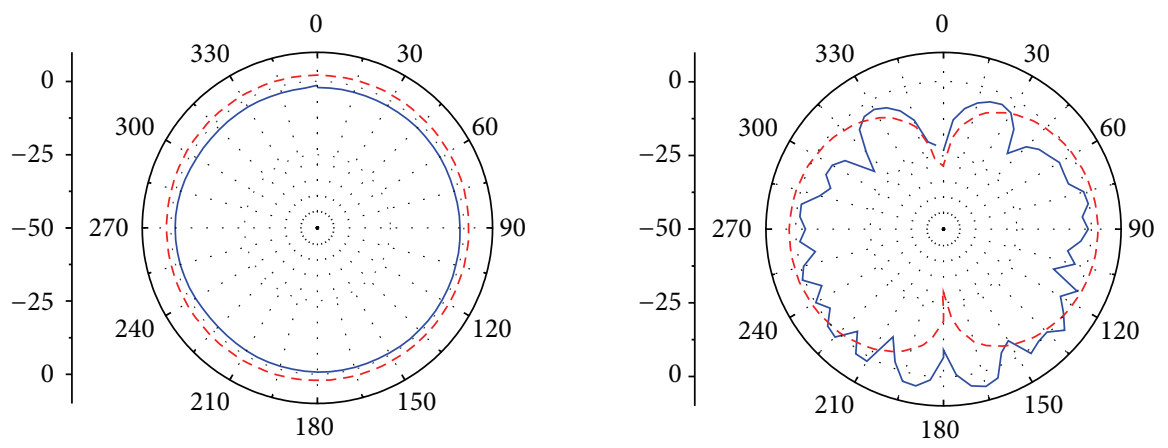

- - - Simulated

--- Simulated

— Measured

(a)
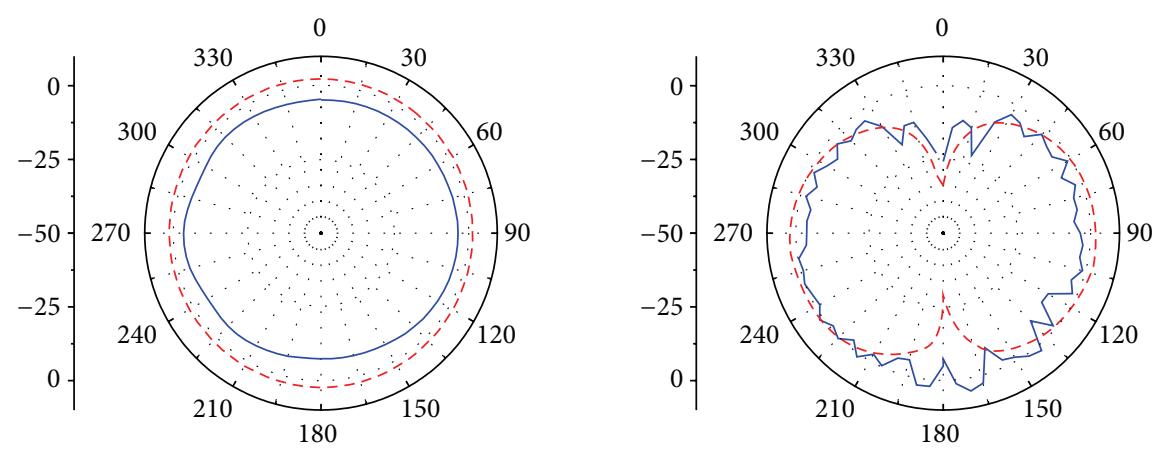

-- Simulated
- Measured

- - - Simulated

- Measured

(b)
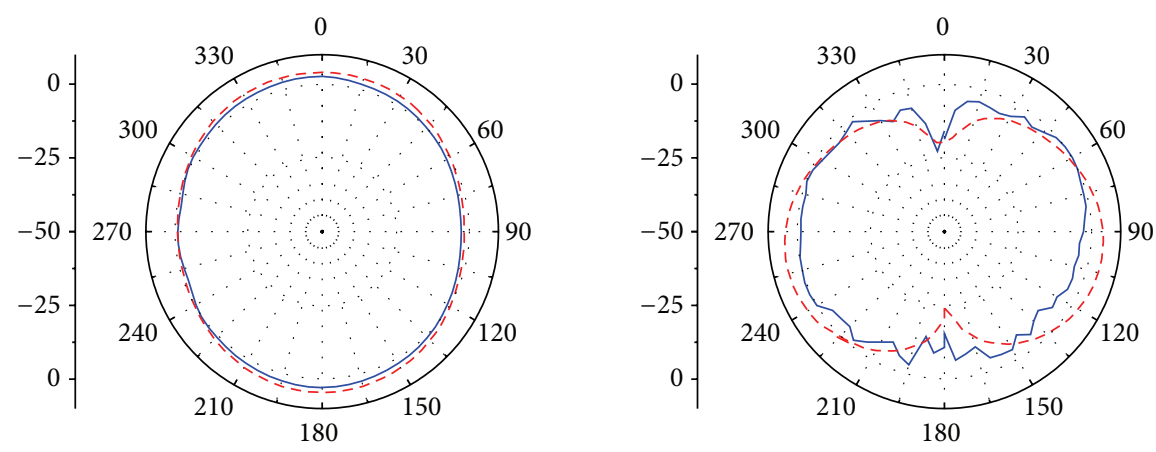

$\begin{array}{cc}--- & \text { Simulated } \\ - & \text { Measured }\end{array}$

-. - Simulated

Measured

$X Y$-plane

$Z X$-plane

(c)

FIGURE 7: Simulated and measured radiation patterns of the proposed antenna at (a) $2.4 \mathrm{GHz}$, (b) $3.5 \mathrm{GHz}$, and (c) $5.5 \mathrm{GHz}$. 


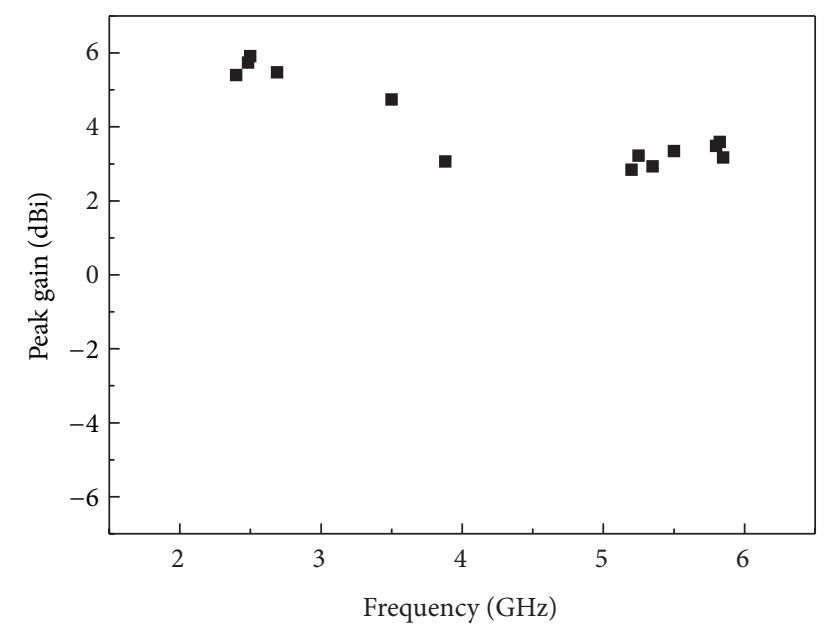

- Peak gain

FIGURE 8: Measured peak gain of the proposed antenna at operational frequency bands.

\section{References}

[1] Y.-F. Liu, K.-L. Lau, Q. Xue, and C.-H. Chan, "Experimental studies of printed wide-slot antenna for wide-band applications," IEEE Antennas and Wireless Propagation Letters, vol. 3, no. 1, pp. 273-275, 2004.

[2] Y. Xu, Y.-C. Jiao, and Y.-C. Luan, "Compact CPW-fed printed monopole antenna with triple-band characteristics for WLAN/WiMAX applications," Electronics Letters, vol. 48, no. 24, pp. 1519-1520, 2012.

[3] S. Verma and P. Kumar, "Compact triple-band antenna for WiMAX and WLAN applications," Electronics Letters, vol. 50, no. 7, pp. 484-486, 2014.

[4] C.-Y. Huang and E.-Z. Yu, "A slot-monopole antenna for dual-band WLAN applications," IEEE Antennas and Wireless Propagation Letters, vol. 10, pp. 500-502, 2011.

[5] S. C. Basaran, U. Olgun, and K. Sertel, "Multiband monopole antenna with complementary split-ring resonators for WLAN and WiMAX applications," Electronics Letters, vol. 49, no. 10, pp. 636-638, 2013.

[6] S. Jo, H. Choi, B. Shin, S. Oh, and J. Lee, "A CPW-fed rectangular ring monopole antenna for WLAN applications," International Journal of Antennas and Propagation, vol. 2014, Article ID 951968, 6 pages, 2014.

[7] H.-W. Liu, C.-H. Ku, and C.-F. Yang, "Novel CPW-fed planar monopole antenna for WiMAX/WLAN applications," IEEE Antennas and Wireless Propagation Letters, vol. 9, pp. 240-243, 2010.

[8] M. A. Antoniades and G. V. Eleftheriades, "A compact multiband monopole antenna with a defected ground plane," IEEE Antennas and Wireless Propagation Letters, vol. 7, pp. 652-655, 2008. 

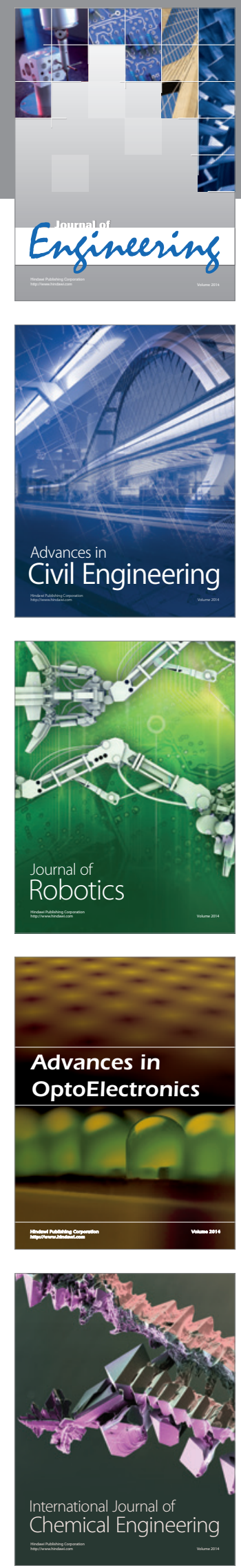

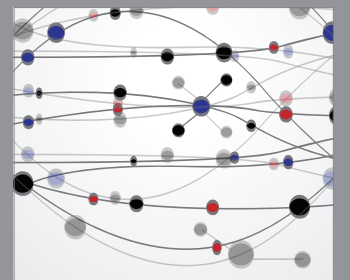

The Scientific World Journal
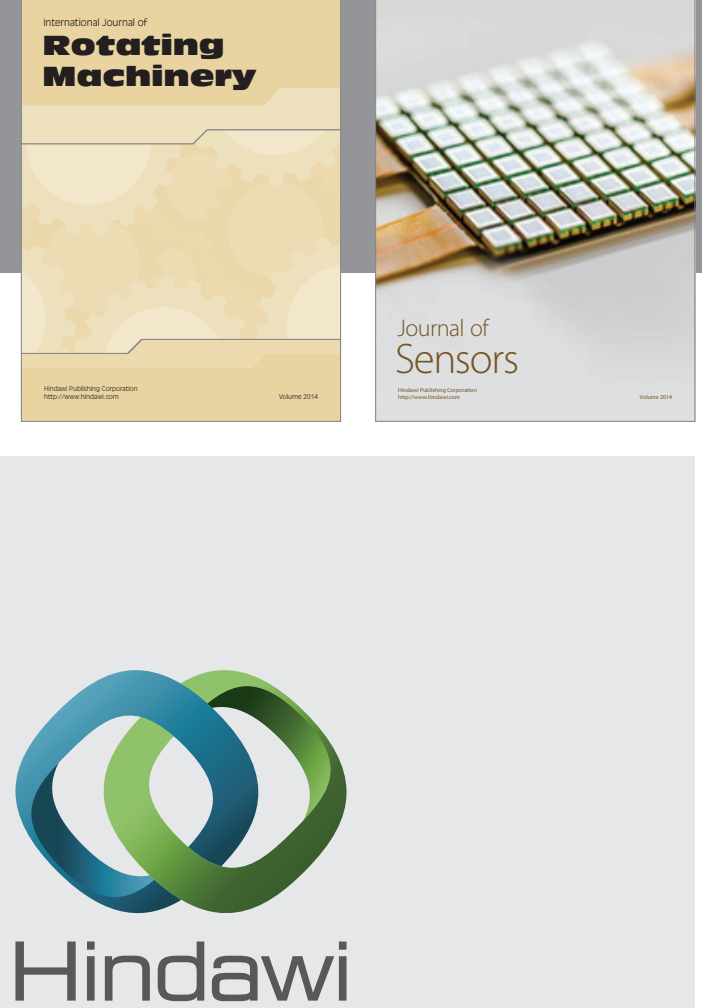

Submit your manuscripts at http://www.hindawi.com
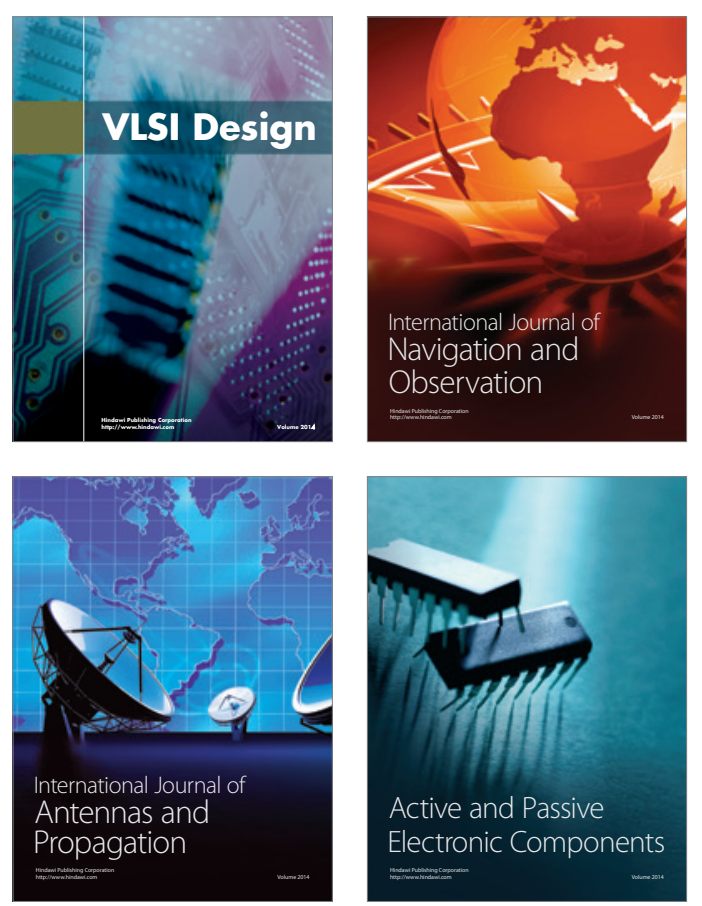
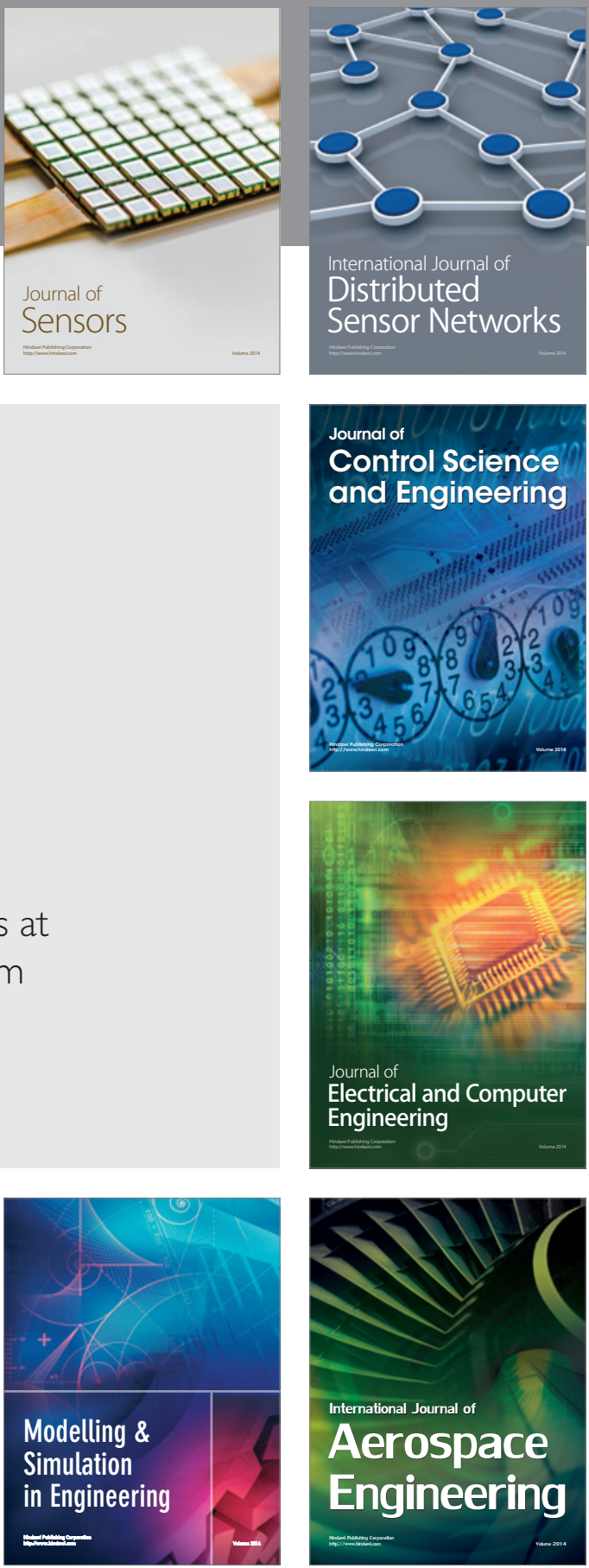

Journal of

Control Science

and Engineering
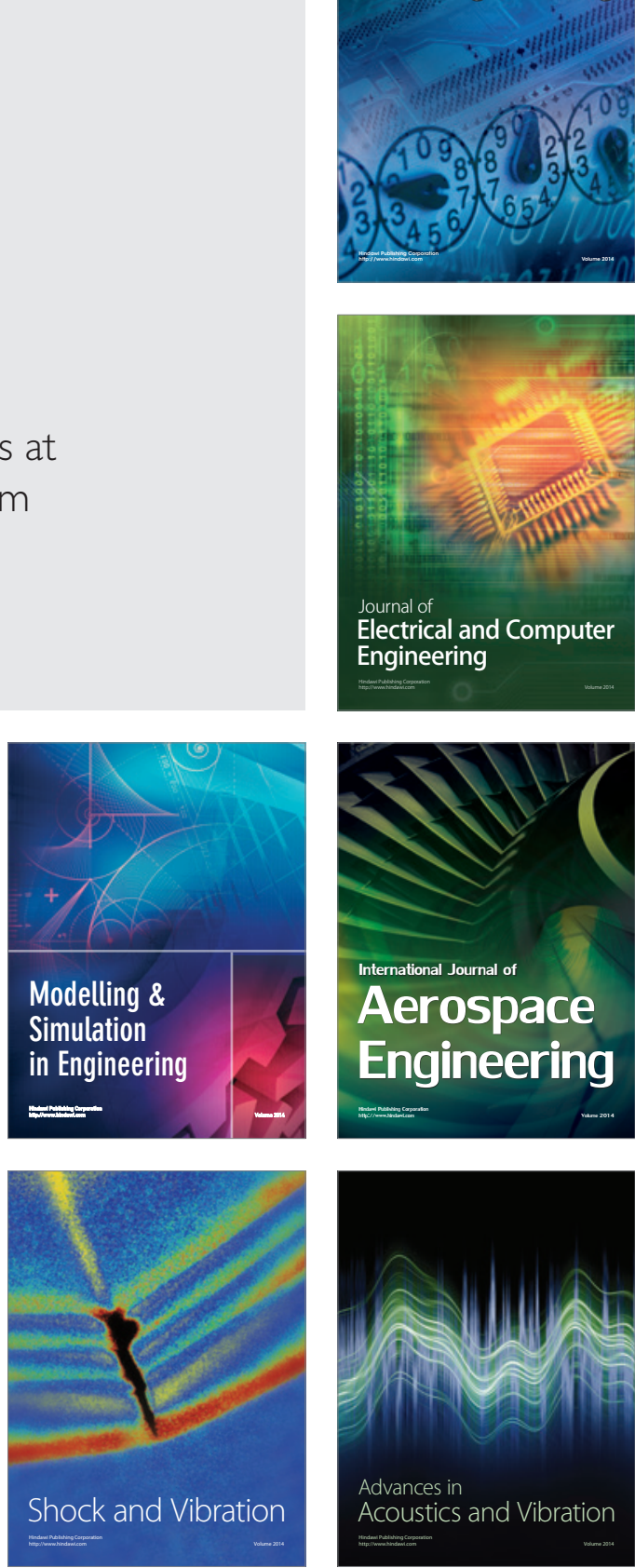